\title{
Categorization of Fibers and their Influence on Concrete Properties
}

\author{
G.Lizia Thankam, T. R. Neelakantan
}

\begin{abstract}
Incorporation of the different types of fibers in the concrete composite has become a conventional approach in the recent era. The culminating enhancement of various properties of the cement and concrete composite by the instigation of the fibers and their feasibility to the various environmental conditions make them stand out in the present scenario. Furthermore, the hybrid fibers in various combinations have a synergetic effect which causes the advancement of two more parameters of the concrete composites. This paper lines up the transformations in the physical, chemical and the mechanical properties of fiber reinforced concrete. This provides the abbreviation of the classification of fibers and the impact of mono fibers and hybrid fibers as well in the concrete composites. Thus the different literature reviews throw light on the necessity, choosing the right fiber and their consecutive effects on the type of concrete composite used. Steel fibers and polypropylene fibers were noted to improve the mechanical strength to an extend whereas glass and carbon fibers tend to have the same effect in lower level which had also become a hazardous one owing to the various chemical reactions. Though the natural fibers have good durable properties, it is used less due to its degradable nature
\end{abstract}

Key words: fiber reinforced concrete, mono fibers, hybrid fibers, classification of fibers, natural fibers.

\section{INTRODUCTION}

Though the usage of cement and cementitious materials in concrete is inexorable, the low strain capacity and tensile strength of these materials make them to be brittle in nature. The minor cracks and brittleness of the concrete structures are visibly minimized by the addition of the fibers [1]. The durability performance, ductility and toughness were also increased with the addition of fibers. This is achieved by limiting the initiation and propagation of cracks [2]. Polymeric, natural and metallic fibers are used for the enhancement of the concrete properties [3].A single type of fiber only improves any one property of the concrete composite, whereas a hybrid fiber improves two or more parameter of the concrete structures [4] by deriving the benefits from individual fibers which in turn creates a synergetic response in the concrete structures [5].

Revised Manuscript Received on December 05, 2019.

* Correspondence Author

G.Lizia Thankam *, Department of Civil Engineering, Kalasalingam Academy of Research and Education,Virudhunagar, India. Email: g.liziathankam@klu.ac.in

T. R. Neelakantan*, Department of Civil Engineering, Kalasalingam Academy of Research and Education,Virudhunagar, India. Email: neelakantan@klu.ac.in

\section{CATEGORIZATION OF FIBERS}

Different types of mono fibers or hybrid fibers are used to enhance various properties like creep, shrinkage, micro cracks, workability, tensile strength and compressive strength of the concrete structures. On the basis of literatures review various types of fibers are detailed in this paper.

\section{A. Steel fibers}

Being the most commonly used fiber for most of the non structural and structural elements [6], when steel fiber is introduced in concrete at various contents by the volume of concrete, utmost compressive strength were noticed at $1.5 \%$ fiber in concrete showing $15.3 \%$ higher strength than the high strength concrete obtained without fiber [7]. It was reported in another study that the concrete mix developed with smaller fibers reciprocated larger compressive strength than the concrete with long fiber [8]. Laboratory research was conducted on fiber reinforced concrete (FRC) in the year 1963 in the United States [9]. The splitting tensile strength of concrete was noticed to rise $159.8 \%$ higher than the unreinforced concrete when incorporated with $1.5 \%$ hooked end steel fiber [10]. Steel fiber along with pozzolanic materials was found to be effective and recommended in another study [11].Upon the addition of $2 \%$ of hooked end steel fiber having the energy absorption properties and flexural strength were found to be higher than the concrete with crimped and straight fibers [12]. The creep of concrete were also notably reduced up to $24 \%$ than the plain concrete in steel fiber reinforced cement composites[13].Steel fibers in concrete restricts the extension of drying and plastic shrinkage cracks and in turn minimizing the permeability of concrete.

\section{B. Polypropylene fiber}

One of the most commonly used and compatible fiber with almost all of the concrete types and chemical admixtures are the polypropylene fiber. They are developed from the propylene gas by conventional melt spinning. By the increase in the polypropylene fiber volume fraction, the workability of concrete declined proportionally [14], which can be rectified by the addition of high range water reducing admixtures [15] Upon the addition of $1.5 \%$ of polypropylene fiber in concrete, the split tensile, flexural and compressive strength were improved [16].Whereas in another study, the compressive strength of concrete increased up to $17 \%$ from $4 \%$ upon the addition of polypropylene fibers [17]. 
The split tensile strength and flexural strength were reported to increase with the increasing fiber content up to $9 \mathrm{~kg} / \mathrm{m}^{3}$ by the conduction of tensile stress to the fibers which in turn arrests the micro cracks [18]. Thus the polypropylene fibers are widely used since it greatly improves fracture parameters [19], arrests the plastic cracks [20] and also reduces the plastic shrinkage [21].

\section{Glass fibers}

Glass fibers were first used in Russia and were noted to corrode by the alkaline cement matrix which later on induced to develop the alkali resistant glass fibers. The polymer plate jackets developed with glass fibers effectively prevented the longitudinal bar buckling in columns [22]. However large deflections and crack width were noticed in the concrete members developed with reinforced polymer bars due to the lower modulus of elasticity of the fiber compared with that of the steel fiber [23]. In another study when 20 various types of glass fiber reinforced polymer bars are tested in three variant alkaline environment under different tensile loading (22-68\% of ultimate strength) along with the stress corrosion mechanism by micro structural analysis. Stress dominated, diffusion dominated and crack propagation dominated stress corrosion mechanisms were identified under different sustained stress levels [24]. Thus the glass fiber is much pronounced in the improvement of stability of the concrete structures.

\section{Carbon fibers}

The low weight, high stiffness and high strength made the carbon fibers to be an important material in the aerospace industry which is later on very commonly used in the construction industry also due to its extended benefits. The mechanical properties of the concrete mixture were noted to improve by the high resistance to cracks and permanent deformation in the flexible pavement [25]. The electrical conductivity and the performance were better in carbon fiber included pavement than the graphite one. Thus it insists the clearance of snow and ice by thermo-electrical techniques during the winter season in the highways [26] [27].

\section{E. Asbestos fibers}

Asbestos fibers are developed from the rocks containing asbestos which is the crushed to produce the fibrous material (asbestos). It was earlier referred as the miracle mineral in the $18^{\text {th }}$ century by the Greek and Romans. Asbestos fibers can be either added to the concrete or to the cement. In a study of the plain and modified asphalt mixtures, the hydraulic properties and the void contents were studied and compared. One polymer modifier was introduced in two different mixtures and asbestos was used in another one modifying the base matrix. After the fatigue test, the hydraulic properties and void content were noticed to decrease for plain and SBS modified mixture, whereas no decrease in no decrease in void content with minimal rutting and unchanged drainage properties were observed in the mixture with asbestos fiber[28].

\section{F. Hybrid fiber}

Hybrid fibers are developed to exhibit a synergetic effect in concrete by extracting the beneficiary from two or more types of fibers in order to enhance the overall response of the structure. Various types of hybrid fibers are reviewed below:

\section{- Polymer-Polymer hybrid fiber}

In a detailed study when two volume fractions of $1.2 \%$ and $2 \%$ of polypropylene and polyvinyl alcohol fibers having various hybrid fiber ratios are used as reinforcement, it improved the ductility behavior at the best for a polyvinyl alcohol/polypropylene ratio of 75/25\% [29]. The impacts of the polypropylene/polyethylene polymeric hybrid fiber as reinforcement on the mechanical and rheological properties of the composites were correlated with Polyacrylonitrile (PAN) fibers of bean shape. The polypropylene/polyethylene hybrid type fibers were blended together by six packages of filaments by extruding process and they were recorded to enhance the mechanical properties by $40 \%$ for the hybrid fiber included cementitious composites [30]. The compressive strength, flexural strength and splitting tensile strength were noticed to increase than the mono fiber reinforced concrete when the polypropylene fibers of macro mono filament and microfiber of various percentages are included in the cementitious matrix.Thus when two various polymer fibers are used together in cementitious matrix, it tend to enhance the strain capacity, strength and ductility

\section{- Polymer-Natural fiber}

When steel fiber and palm fiber are introduced together at $2 \%$ of total volume fraction in the concrete composite, the residual strength and flexural strength are visibly increased when compared with the mono fiber concrete composite [31]. Though the incorporation of natural fibers in concrete structures develops mineralization in alkaline environmental conditions [32], they also play major role in the cost reduction of the weight of the structures. The study of hybrid fiber reinforced concrete having natural fibers are limited and these toughness enhancing polymer-natural hybrid fibers are to be experimented and studied more in future.

\section{- Steel-Steel hybrid fiber}

Hybridization of macro (fiber diameter $=0.8 \mathrm{~mm}$ ) and micro (fiber diameter $=0.4$ and $0.45 \mathrm{~mm}$ ) crimped steel fibers i.e., use of smaller crimped steel fiber with alike length improved the flexural toughness of the concrete [33].The tensile strength, cracking and toughness are visibly improved with the addition of both carbon steel hooked end fiber and amorphous metallic straight fiber in the fiber reinforced concrete in another study [34]. When long and short corrugated hybrid steel fiber are introduced at 1, 1.5 and $2 \%$ into the concrete mix resulting in a good workable concrete but no positive enhancement were observed in the residual strength and flexural toughness of the fiber reinforced concrete[35]. The tensile strength and split tensile strength were notably higher for a blend of steel and brass coated steel at $1.5 \%$ and $2 \%$ respectively when the seismic behavior of the beam- column joints for three different fibers namely brass coated steel fiber; polypropylene fiber and hooked end steel fiber were analyzed under cyclic loading. Also the damage tolerance capacity, member ductility and shear capacity were found higher than the conventional concrete [36]. Altogether hybrid steel fibers are good enough to uplift the mechanical and durability properties of the concrete composite. 


\section{- Steel- Polymer hybrid fiber:}

The multiple cracking and strain hardening behavior were investigated for the hybrid fibers blended with polyethylene and steel fibers. A critical fiber volume fraction concept was proposed upon the experimental verification which can be tuned by ideal picking of fiber diameter, length and interfacial bonding strength. The fibers with lower modulus behaved better during multiple cracking and strain hardening in the post cracking zone. Elevated polyethylene fiber content improved the strain capacity in the hybrid system [37]. Compared to the mono fiber reinforced concrete, the hybrid -polypropylene-steel FRC in lower fiber volume fraction of $0.5 \%$ enhanced the mechanical performance of the concrete. Similar results with $0.5 \%$ steel fiber reinforced concrete were noted when 03 volume $\%$ of steel fiber and polypropylene fibers were replaced [38].In another study of partial replacement of steel fibers with polyvinyl alcohol fiber at a total fiber volume fraction of $2 \%$, both flexural toughness and flexural strength were enhanced developing the best energy absorption capacity at $1.75 \%$ steel $+0.25 \%$ polyvinyl alcohol hybrid composite mix. The deformability and ductility were also enhanced due to the delay in the development of macro cracks by the steel fibers with lower elastic modulus [39]. The shear behaviors of FRC with two different combinations of fibers were studied. The hybrid steel/polypropylene fibers performed well exhibiting good workability in fresh concrete and better toughness in hardened concrete compared with the steel/ recycled Polyethylene terephthalate fibers [40]. Thus the hybrid steel-polymer fiber was found to enhance the durability of concrete mix at various conditions.

\section{F. Natural fibers}

The natural fibers are ample and available locally in making concrete. Using fibers to improve the durability and strength of brittle materials already exists. Natural fibers have higher modulus of elasticity than the vegetable fibers. The highly available sisal leaf fiber from the tropical countries is the most commonly used fiber. The coir fiber from coconut tree is the most feasible fiber for concrete which is less strong when compared to the palm fiber. Even the palm fibers are utilized as reinforcement in the tropical countries for developing concrete structures. After extraction of the bamboo fibers by hammering of short bamboo sticks, the mechanical properties of bamboo FRC were analyzed [41]. Experimental investigation on the yeast fiber reinforced concrete by the addition of $10 \mathrm{~g}$ of yeast granules into a $2 \mathrm{Kg}$ concrete mass showed better flow ability and enhanced strength parameters [42]. The kenaf fiber reinforced composites were reported to improve the flexural strength up to $36 \%$ than the normal concrete composite [43]. Thus the natural fibers are very common and highly used by most of the researchers nowadays [44]. Natural fibers are renewable, low cost and they are non hazardous to the ecological system [45]. But on the other side they have lower thermal stability and higher degradation of strength [46].

\section{CONCLUSION}

The summarized review of the literatures were put together and concluded as follows:

- $15.3 \%$ higher strength by the addition of steel fibers than the normal cement concrete.
- Polypropylene fibers improves the fracture strength and compressive strength up to $17 \%$

- Glass and carbon fibers tend to improve the mechanical properties of the concrete composites but they were also noted to be hazardous to the environment.

- The natural fibers were reported to increase the durability of the concrete structures; however they are used less due to their lower stability and degradation nature.

- Hybrid fibers improve the mechanical as well as durability properties of concrete through the synergetic effect than any other mono form of fiber reinforced concrete.

\section{REFERENCES}

1. Bentur, Arnon, and Sidney Mindess. Fibre reinforced cementitious composites. Crc Press, 2006.

2. Jamshidi, M., and M. Karimi. "Characterization of polymeric fibers as reinforcements of cement-based composites." Journal of applied polymer science 115, no. 5 (2010): 2779-2785.

3. Brandt, Andrzej M. Cement-based composites: materials, mechanical properties and performance. CRC Press, 2005.

4. El-Mal, HSS Abou, A. S. Sherbini, and H. E. M. Sallam. "Mode II fracture toughness of hybrid FRCs." International Journal of Concrete Structures and Materials 9, no. 4 (2015): 475-486.

5. Shu, Xiang, Ryan K. Graham, Baoshan Huang, and Edwin G. Burdette. "Hybrid effects of carbon fibers on mechanical properties of Portland cement mortar." Materials \& Design (1980-2015) 65 (2015): 1222-1228.

6. Dvorkin, L., and O. Dvorkin. "Basics of concrete science." St-Petersburg: Stroy-Beton (2006). Chapter 7: pp 135-144

7. Song, P. S., and S. Hwang. "Mechanical properties of high-strength steel fiber-reinforced concrete." Construction and Building Materials 18, no. 9 (2004): 669-673.

8. Chen, Wai-Fah, and J. L. Carson. "Stress-strain properties of random wire reinforced concrete." In Journal Proceedings, vol. 68, no. 12, pp. 933-936. 1971.

9. Romualdi, James P., and Gordon B. Batson. "Behavior of reinforced concrete beams with closely spaced reinforcement." In Journal Proceedings, vol. 60, no. 6, pp. 775-790. 1963.

10. Wafa, Faisal F., and Samir A. Ashour. "Mechanical properties of high-strength fiber reinforced concrete." Materials Journal89, no. 5 (1992): 449-455.

11. Tsai, Chih-Ta, Lung-Sheng Li, Chien-Chic Chang, and Chao Lung Hwang. "Durability design and application of steel fiber reinforced concrete in Taiwan." Arabian Journal for Science \& Engineering (Springer Science \& Business Media BV) 34 (2009).

12. Soroushian, Parviz, and Ziad Bayasi. "Fiber type effects on the performance of steel fiber reinforced concrete." Materials Journal 88, no. 2 (1991): 129-134.

13. Mangat, P. S., and M. Motamedi Azari. "Compression creep behaviour of steel fibre reinforced cement composites." Materials and Structures 19, no. 5 (1986): 361-370.

14. Patel, Mehul J., and S. M. Kulkarni. "Effect of Polypropylene Fibre on The High Strength Concrete." Journal of Information Knowledge and Research in Civil Engineering 2, no. 2 (2012): 127.

15. Thirumurugan, S., and A. Sivakumar. "Compressive Strength Index of Crimped Polypropylene Fibres in High Strength Cementitious Matrix." World Appl. Sci. J 24, no. 6 (2013): 698-702.

16. Patel, Priti A., Atul K. Desai, and Jatin A. Desai. "Evaluation of engineering properties for polypropylene fibre reinforced concrete." International journal of advanced engineering technology 3 , no. 1 (2012): 42-45. 
17. Anbuvelan, K., M. M. Khadar, M. Lakshmipathy, and K. S. Sathyanarayanan. "Studies on properties of concretes containing polypropylene, steel and reengineered plastic shred fibre." Indian concrete journal 81, no. 4 (2007): 38-44.

18. Gencel, Ozel, Cengiz Ozel, Witold Brostow, and G. Martinez-Barrera. "Mechanical properties of self-compacting concrete reinforced with polypropylene fibres." Materials Research Innovations 15, no. 3 (2011): 216-225

19. Zhang, Peng, and Qingfu Li. "Fracture Properties of Polypropylene Fiber Reinforced Concrete Containing Fly Ash and Silica Fume." Research Journal of Applied Sciences, Engineering and Technology 5, no. 2 (2013): 665-670

20. Hsie, Machine, Chijen Tu, and P. S. Song. "Mechanical properties of polypropylene hybrid fiber-reinforced concrete." Materials Science and Engineering: A 494, no. 1-2 (2008): 153-157.

21. Xiao, Jianzhuang, and H. Falkner. "On residual strength of high-performance concrete with and without polypropylene fibres at elevated temperatures." Fire safety journal 41, no. 2 (2006): 115-121.

22. Wang, Yung C., and Jose I. Restrepo. "Investigation of concentrically loaded reinforced concrete columns confined with glass fiber-reinforced polymer jackets." Structural Journal98, no. 3 (2001): 377-385.

23. Toutanji, Houssam A., and Mohamed Saafi. "Flexural behavior of concrete beams reinforced with glass fiber-reinforced polymer (GFRP) bars." Structural Journal 97, no. 5 (2000): 712-719

24. Benmokrane, Brahim, Peng Wang, Tan Minh Ton-That, Habib Rahman, and Jean-Francois Robert. "Durability of glass fiber-reinforced polymer reinforcing bars in concrete environment." Journal of Composites for Construction 6, no. 3 (2002): 143-153.

25. Jahromi, Saeed Ghaffarpour, and Ali Khodaii. "CARBON FIBER REINFORCED ASPHALT CONCRETE." Arabian Journal for Science \& Engineering (Springer Science \& Business Media $B V) 33$ (2008).

26. Wu, Shaopeng, Liantong Mo, Zhonghe Shui, and Zheng Chen "Investigation of the conductivity of asphalt concrete containing conductive fillers." Carbon 43, no. 7 (2005): 1358-1363

27. Liu, Xiaoming, Shaopeng Wu, Ning Li, and Bo Gao "Self-monitoring application of asphalt concrete containing graphite and carbon fibers." Journal of Wuhan University of Technology-Mater. Sci. Ed. 23, no. 2 (2008): 268.

28. Huet, M., A. De Boissoudy, J. C. Gramsammer, A. Bauduin, and J. Samanos. "Experiments with porous asphalt on the Nantes fatigue test track." Transportation Research Record1265 (1990).

29. Pakravan, Hamid Reza, Masoud Latifi, and Masoud Jamshidi. "Ductility improvement of cementitious composites reinforced with polyvinyl alcohol-polypropylene hybrid fibers." Journal of Industrial Textiles 45, no. 5 (2016): 637-651.

30. Silva, E. R., J. F. J. Coelho, and J. C. Bordado. "Strength improvement of mortar composites reinforced with newly hybrid-blended fibres: Influence of fibres geometry and morphology." Construction and Building Materials 40 (2013): 473-480.

31. Dawood, Eethar Thanon, and Mahyuddin Ramli. "Effects of the fibers on the properties of high strength flowing concrete." $K S C E$ Journal of Civil Engineering 18, no. 6 (2014): 1704-1710.।

32. Mohr, B. J., H. Nanko, and K. E. Kurtis. "Durability of kraft pulp fiber-cement composites to wet/dry cycling." Cement and Concrete Composites 27, no. 4 (2005): 435-448.

33. Banthia, Nemkumar, and M. Sappakittipakorn. "Toughness enhancement in steel fiber reinforced concrete through fiber hybridization." Cement and Concrete Research 37, no. 9 (2007): 1366-1372.

34. Hameed, Rashid, Anaclet Turatsinze, Frédéric Duprat, and Alain Sellier. "A study on the reinforced fibrous concrete elements subjected to uniaxial tensile loading." KSCE Journal of Civil Engineering 14, no. 4 (2010): 547-556.

35. Mohammadi, Yaghoub, S. P. Singh, and S. K. Kaushik. "Properties of steel fibrous concrete containing mixed fibres in fresh and hardened state." Construction and Building Materials 22, no. 5 (2008): 956-965.

36. Chidambaram, R. Siva, and Pankaj Agarwal. "Seismic behavior of hybrid fiber reinforced cementitious composite beam-column joints." Materials \& Design 86 (2015): 771-781.

37. Ahmed, Shaikh Faiz, Mohamed Maalej, and P. Paramasivam. "Analytical model for tensile strain hardening and multiple cracking behavior of hybrid fiber-engineered cementitious composites." Journal of materials in civil engineering 19, no. 7 (2007): 527-539.

38. Yao, Wu, Jie Li, and Keru Wu. "Mechanical properties of hybrid fiber-reinforced concrete at low fiber volume fraction." Cement and concrete research 33, no. 1 (2003): 27-30.

39. Zhang, Peng, and Qingfu Li. "Fracture Properties of Polypropylene Fiber Reinforced Concrete Containing Fly Ash and Silica Fume." Research Journal of Applied Sciences, Engineering and Technology 5, no. 2 (2013): 665-670.

40. Karthik, M. P., and D. Maruthachalam. "Experimental study on shear behaviour of hybrid Fibre Reinforced Concrete beams." KSCE Journal of Civil Engineering 19, no. 1 (2015): 259-264.

41. Pakotiprapha, B., R. P. Pama, and S. L. Lee. "Analysis of a Bamboo Fiber-Cement Paste Composite." JOURNAL OF FERROCEMENT-BANGKOK 13, no. 2 (1983): 141-159.

42. R. Ramanathan, S. Chockalingam and R. Sethunarayanan. Yeast Fibre Reinforced Concrete. Proc., ISFRC, Vol. II, Madras, India, 1987.

43. Yousif, B. F., A. Shalwan, C. W. Chin, and K. C. Ming. "Flexural properties of treated and untreated kenaf/epoxy composites." Materials \& Design 40 (2012): 378-385.

44. Di Bella, G., V. Fiore, G. Galtieri, C. Borsellino, and A. Valenza "Effects of natural fibres reinforcement in lime plasters (kenaf and sisal vs. Polypropylene)." Construction and Building Materials 58 (2014): 159-165

45. Davoodi, M. M., S. M. Sapuan, Desa Ahmad, Aidy Ali, A. Khalina, and Mehdi Jonoobi. "Mechanical properties of hybrid kenaf/glass reinforced epoxy composite for passenger car bumper beam." Materials \& Design 31, no. 10 (2010): 4927-4932.

46. Alawar, Ahmad, Ahmad M. Hamed, and Khalifa Al-Kaabi. "Characterization of treated date palm tree fiber as composite reinforcement." Composites Part B: Engineering 40, no. 7 (2009): 601-606.

\section{AUTHOR PROFILE}

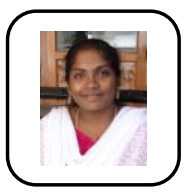

G.Lizia Thankam is a Research Scholar at Kalasalingam Univesity who graduated both her UG and PG degree from Karunya Uiversity, Coimbatore. She preferred to be in teaching till 2018 at Karunya University,Coimbatore and Kalasaligam University,Virudhunagar. She has modest publications in reputed journals.

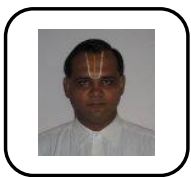

Dr. T.R. Neelakantan is a Senior Professor in Civi Engineering and Director - Accreditation and Ranking at Kalasalingam Academy of Research and Education, Tamilnadu. He obtained his Ph.D. degree in Civil Engineering from Anna University in the year 1998. His working experiences are from Anna University, IIT-Madras, SASTRA Deemed University and the University of Kentucky, Lexington, USA. He published more than 60 articles in reputed journals, and handled many government and private funded projects both in India and USA. 